\title{
Predictive factors of increased surgical drain output after thyroid lobectomy: a retrospective study
}

\author{
Chih-Yu Chen ${ }^{1}$, Yu-Lung Chiu ${ }^{2}$, Sarina Rajbhandari ${ }^{3}$, Sheng-Yao Cheng ${ }^{1}$, Hung-Che Lin ${ }^{1}$, \\ Yueng-Hsiang $\mathrm{Chu}^{1}$, Jih-Chin Lee ${ }^{1}$ \\ ${ }^{1}$ Department of Otolaryngology—Head and Neck Surgery, Tri-Service General Hospital, ${ }^{2}$ School of Public Health, National Defense Medical \\ Center, Taipei; ${ }^{3}$ Department of Otolaryngology_-Head and Neck Surgery, Shankarapur Hospital, Kathmandu, Nepal \\ Contributions: (I) Conception and design: CY Chen, JC Lee; (II) Administrative support: JC Lee, YH Chu; (III) Provision of study materials or \\ patients: All authors; (IV) Collection and assembly of data: CY Chen, SY Cheng; (V) Data analysis and interpretation: CY Chen, YL Chiu, HC Lin; \\ (VI) Manuscript writing: All authors; (VII) Final approval of manuscript: All authors. \\ Correspondence to: Jih-Chin Lee, MD. Department of Otolaryngology—Head and Neck Surgery, Tri-Service General Hospital, National Defense \\ Medical Center, No. 325, Cheng-Kung Road Section 2, Taipei 114. Email: doc30450@gmail.com.
}

Background: Thyroid lobectomy is one of the most common operations for thyroid lesions. Life-threatening complications can occur; these include post-operative bleeding with airway compression caused by hematoma. Given this risk, prophylactic drains are routinely used in our practice. The aim of this study was to identify factors that influence the total drainage volume (TDV).

Methods: From 2016 to 2017, a total of 89 consecutive patients with thyroid lobectomy performed by the same surgeon were included in the study. The demographic characteristics of the patients, TDV, fine needle aspiration cytology, hospitalization day, operation time, thyroid gland size, and blood test results were retrospectively recorded from the hospital database. Spearman's rank correlation and multivariate regression were used to analyze the association of factors with the TDV.

Results: The median TDV was $56 \mathrm{~mL}$, and there was a positive correlation between age, weight, blood sugar, gland size, hospitalization day, operation time, and TDV. Multivariate regression analysis revealed that male sex ( $\beta=19.684 ; 95 \%$ CI, 7.998-31.371; $\mathrm{P}=0.001)$, higher blood sugar $(\beta=0.173 ; 95 \% \mathrm{CI}, 0.087-0.260$; $\mathrm{P}<0.001)$, and larger thyroid gland size $(\beta=0.069 ; 95 \% \mathrm{CI}, 0.008-0.130 ; \mathrm{P}=0.027)$ were independent risk factors for TDV.

Conclusions: The TDV primarily depends on male sex, larger thyroid gland, and higher blood sugar level. Patients with these factors should undergo meticulous hemostasis and bleeding should be carefully monitored in the perioperative period.

Keywords: Suction drainage; thyroid lobectomy; thyroidectomy

Submitted Jun 30, 2019. Accepted for publication Sep 27, 2019.

doi: 10.21037 /gs.2019.10.05

View this article at: http://dx.doi.org/10.21037/gs.2019.10.05

\section{Introduction}

Thyroid lobectomy is one of the most commonly performed surgical interventions for thyroid lesions. This operation involves removing the half of the affected thyroid gland and is a relatively safe surgical procedure. The main indications for thyroidectomy are the presence of thyroid nodules, thyroid carcinoma, and multinodular goiters.
As the thyroid gland is an organ with a high vascular perfusion, second only to the adrenal glands, post-operative bleeding is a major complication of thyroid surgery (1). Currently, there is no consistent view of placing the drain after thyroidectomy. The purpose of having the drain is to create a negative pressure on the wound bed and obliterating the dead space; by doing so, hope to prevent hematoma or seroma and shorten the hospital stay. Although one study 


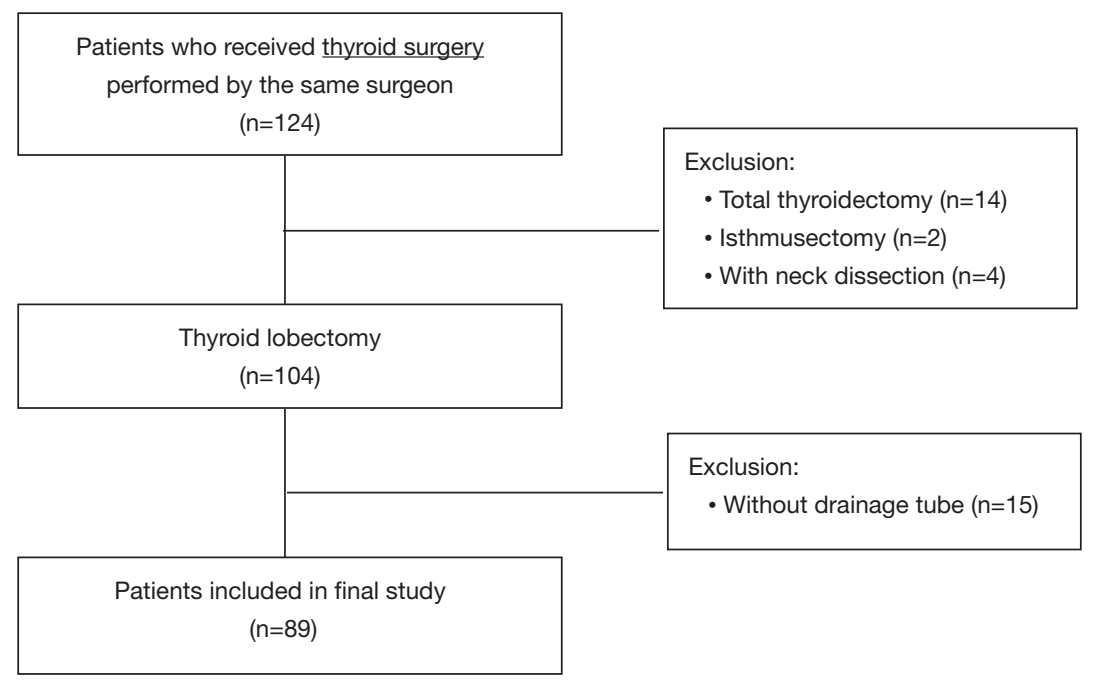

Figure 1 Patient selection.

revealed suction drain may increase the amount of drainage during the first 24-48 hours postoperatively (2).

In our practice, we use drains routinely in all thyroidectomy patients. Some lobectomy procedures have a very dry surgical dissection and may still develop significant postoperative drainage. Compressive postoperative cervical hematoma can be a life-threatening complication from loss of airway. A significant number of patients with a postoperative hematoma present $>6$ hours after thyroidectomy (3).

The present study aims to evaluate the factors affecting the post-operative drainage volume post thyroid lobectomy, performed by the same surgeon.

\section{Methods}

\section{Study participants}

Between January 2016 and December 2017, a total of 124 consecutive patients who underwent thyroid surgery for various indications, conducted by the same surgeon, were selected for data analysis. Fourteen patients who underwent a total thyroidectomy, 2 patients who underwent an isthmusectomy, 4 patients who underwent neck dissection in parallel to a thyroid lobectomy, and 15 patients who received surgery without a drain (fibrin sealant was used during the operation), were excluded from the study. Finally, 89 patients were included in further analysis (Figure 1).

\section{Preoperative preparation}

A complete exam of the head and neck, including an evaluation of vocal cord mobility, documentation of the size of the thyroid nodule, and fine needle aspiration were performed. A computed tomography (CT) scan (plain or contrast) of the neck was also carried out and evaluated. Blood tests, such as complete blood count, electrolytes, prothrombin time (PT)/activated partial thromboplastin time (APTT), thyroid stimulating hormone (TSH), and free thyroxine (T4) were routinely checked upon admission.

\section{Data sources}

The age, sex, height, weight, body mass index (BMI), lobectomy side, gland size, operating time, daily drainage volume, glucose level, fine-needle aspiration cytology (FNAC), hospitalization day, and final pathological diagnosis were recorded retrospectively from the hospital database. The thyroid gland size was taken from the pathology report, measured by the responsible pathologist. The operating time was defined as the time from the first incision to the final suture placement.

\section{Technique}

Thyroid lobectomy was performed by a uniform technique of capsular dissection, using traditional unipolar and bipolar cauterization; patients using energy device, such as 
Table 1 Patient characteristics in group

\begin{tabular}{|c|c|c|}
\hline Characteristics & Number & $\%$ \\
\hline \multicolumn{3}{|l|}{ Gender } \\
\hline Male & 27 & 30.34 \\
\hline Female & 62 & 69.66 \\
\hline \multicolumn{3}{|l|}{ Side } \\
\hline Right & 51 & 57.30 \\
\hline Left & 38 & 42.70 \\
\hline \multicolumn{3}{|l|}{ Histopathology } \\
\hline Benign & 70 & 78.65 \\
\hline Malignant & 19 & 21.35 \\
\hline \multicolumn{3}{|l|}{ Lesion } \\
\hline Tumor & 45 & 50.56 \\
\hline Goiter & 44 & 49.44 \\
\hline \multicolumn{3}{|l|}{ FNAC group $^{\dagger}$} \\
\hline $\mathrm{I}+\mathrm{II}^{\ddagger}$ & 32 & 45.07 \\
\hline III & 15 & 21.13 \\
\hline IV & 15 & 21.13 \\
\hline V & 7 & 9.86 \\
\hline $\mathrm{VI}$ & 2 & 2.82 \\
\hline \multicolumn{3}{|l|}{ Hospital day } \\
\hline 2 & 20 & 22.47 \\
\hline 3 & 58 & 65.17 \\
\hline 4 & 10 & 11.24 \\
\hline 5 & 1 & 1.12 \\
\hline
\end{tabular}

${ }^{\dagger}, 18$ patients didn't have the FNAC data; ${ }^{\ddagger}$, due to the similar malignant rate between group I and group II according to the Bethesda system, these two groups were assembled together; $\S$, stands for post-operative hospitalization days. FNAC, fine-needle aspiration cytology.

a LigaSure or Harmonic Scalpel were excluded from this study. Closed suction drains were placed before wound closing, and no fibrin sealant was used during the operation. According to the protocols of our unit, all drains were removed when the drainage volume was less than $15 \mathrm{~mL}$ in 24 hours.

\section{Statistical analysis}

Statistical analyses were performed using the IBM Statistical
Table 2 Patient characteristics

\begin{tabular}{lc}
\hline Characteristics & Median (range) \\
\hline Age (years) & $53(43-61.5)$ \\
$\mathrm{BMI}\left(\mathrm{kg} / \mathrm{m}^{2}\right)$ & $24.69(22.03-27.06)$ \\
$\mathrm{Hb}(\mathrm{g} / \mathrm{dL})$ & $13.50(12.90-14.55)$ \\
WBC $(/ \mu \mathrm{L})$ & $6,650(5,800-7,660)$ \\
Neutrophil $(/ \mathrm{\mu L})$ & $3,759.78(3,311.47-4,676.45)$ \\
TSH $(\mu \mathrm{lU} / \mathrm{mL})$ & $1.47(0.91-2.40)$ \\
Free T4 (ng/dL) & $1.20(1.11-1.33)$ \\
Blood sugar $(\mathrm{mg} / \mathrm{dL})$ & $101[86-123]$ \\
Thyroid gland size $\left(\mathrm{cm}^{3}\right)$ & $49.50(25.99-97.38)$ \\
Total drainage volume $(\mathrm{mL})$ & $56[40-70]$ \\
Post-op hospital day & 3 \\
Operation time (min) & $122.0(104.5-145.5)$
\end{tabular}

BMI, body mass index; WBC, white blood cell; TSH, thyroid stimulating hormone.

Package for the Social Sciences software program version 22 for Windows. The results are shown as the medians and quartiles. Mann-Whitney U, Kruskal-Wallis test, and Spearman's rank correlation were used for the statistical analyses, as appropriate. Univariate and multivariate analyses were used to identify independent risk factors. The results were evaluated within a $95 \%$ confidence range, and a $\mathrm{P}$ value $<0.05$ was considered to be significant.

\section{Results}

A total of 89 patients who underwent thyroid lobectomy were included in this study. No operation related complications, such as wound infection, hematoma, vocal palsy, or hypocalcemia, were noted. The demographic and clinical characteristics are shown in Tables 1,2.

A Pearson correlation coefficient was computed in order to assess the relationship between the variables and the total drainage volume. There were several positive correlations (Table 3). Overall, the positively correlated variables $(\mathrm{P}<0.01)$ were age $(r=0.287, n=89, P=0.006)$, weight $(r=0.324, n=89$, $\mathrm{P}=0.002)$, blood glucose level $(\mathrm{r}=0.455, \mathrm{n}=89, \mathrm{P}<0.001)$, thyroid gland size $(r=0.282, n=89, P=0.007)$, hospitalized day $(r=0.714, n=89, P<0.001)$, operation time $(r=0.441$, $\mathrm{n}=89, \mathrm{P}<0.001)$. Also, the operation time showed positive correlation to the hospital day $(\mathrm{r}=0.389, \mathrm{n}=89, \mathrm{P}<0.001)$. 
Table 3 Pearson correlation between total drainage volume and studied variables

\begin{tabular}{|c|c|c|c|c|c|c|c|}
\hline & Total drainage volume & Age & Weight & Blood sugar & Gland size & Hospital day & Operation time \\
\hline Age & $0.287^{\star \star}$ & 1 & & & & & \\
\hline Weight & $0.324^{\star *}$ & $0.223^{\star}$ & 1 & & & & \\
\hline Blood sugar & $0.455^{\star \star}$ & $0.284^{\star \star}$ & 0.201 & 1 & & & \\
\hline Hospital day & $0.714^{\star *}$ & $0.217^{*}$ & 0.106 & $0.259^{*}$ & 0.095 & 1 & \\
\hline Operation time & $0.441^{\star \star}$ & $0.250^{*}$ & 0.133 & 0.114 & $0.215^{\star}$ & $0.389^{* *}$ & 1 \\
\hline
\end{tabular}

*, correlation is significant at the 0.05 level (two-tailed); ${ }^{* \star}$, correlation is significant at the 0.01 level (two-tailed).

Table 4 Comparisons of right and left regarding the studied variables by the Mann-Whitney test

\begin{tabular}{|c|c|c|c|c|}
\hline Variables & Group & Median (range) & $U$ & Sig. (two-tailed) \\
\hline Hospital day & $\mathrm{R}$ & $3[3-3]$ & 880.50 & 0.388 \\
\hline \multirow[t]{2}{*}{ Operation time (min) } & $\mathrm{R}$ & $126.0(108.0-148.0)$ & 676.00 & 0.015 \\
\hline & $L$ & $113.0(92.5-136.0)$ & & \\
\hline \multirow[t]{2}{*}{ Gland size $\left(\mathrm{cm}^{3}\right)$} & $\mathrm{R}$ & $56.70(29.00-108.00)$ & 856.50 & 0.351 \\
\hline & L & 42.27 (24.53-96.22) & & \\
\hline
\end{tabular}

The Mann-Whitney test (Tables 4,5) indicated that the operation time was longer for right-sided lobectomy $($ median $=126.0 \mathrm{~min})$ than the left side $($ median $=113.0 \mathrm{~min})$ ( $\mathrm{U}=676.00, \mathrm{P}=0.015)$. Moreover, the total drainage volume was greater for men (median $=64 \mathrm{~mL}$ ) than women (median $=54 \mathrm{~mL})(\mathrm{U}=489.00, \mathrm{P}=0.002)$, and the weight was increased in men (median $=72 \mathrm{~kg}$ ) compared to women (median $=60 \mathrm{~kg})(\mathrm{U}=312.50, \mathrm{P}<0.001)$. There was no significant difference between the benign and malignant status, goiter and tumor, and factors related to the sex or side, except for those mentioned above.

The Kruskal-Wallis test (Table 6) was conducted to examine the differences in total drainage volume, hospital days, operation time, and gland size according to the fine needle aspiration cytology groups. Although no significant differences were found, it appears that the gland size became smaller from group I+II to group VI of the Bethesda system $(\mathrm{P}=0.047)$.

The Chi-square test (Table 7) disclosed that the percentage of malignancy was higher from the FNAC group $\mathrm{I}+\mathrm{II}$ to $\mathrm{VI}\left(\chi^{2}=15.591, \mathrm{df}=4, \mathrm{P}=0.004\right)$, which was compatible with the Bethesda system [10] in terms of reporting thyroid cytopathology.

Univariate analysis (Table 8 ) demonstrated the relationship between the risk factors and the total drainage volume. The following eight risk factors were significantly related to the total drainage volume: male gender $(\beta=20.27$, $\mathrm{P}=0.003)$, age $(\beta=0.648, \mathrm{P}=0.005)$, height $(\beta=0.866, \mathrm{P}=0.02)$, weight ( $\beta=0.868, P=0.001)$, $B M I(\beta=2.108, P=0.027)$, free T4 $(\beta=44.20, P=0.012)$, blood sugar $(\beta=0.217, \mathrm{P}<0.001)$, and gland size $(\beta=0.102, P=0.005)$. The following factors had no statistical significance: hemoglobin, white blood cell (WBC) count, neutrophil count, TSH, FNAC groups, sides, benign/malignant, and tumor/goiter.

Multivariate analysis (Table 8) was performed in order to determine whether these parameters were independent risk factors for the total drainage volume. Male sex $(\beta=19.684$; 95\% CI, 7.998-31.371; $\mathrm{P}=0.001)$, higher blood sugar 
Table 5 Comparisons of male and female regarding the studied variables by the Mann-Whitney test

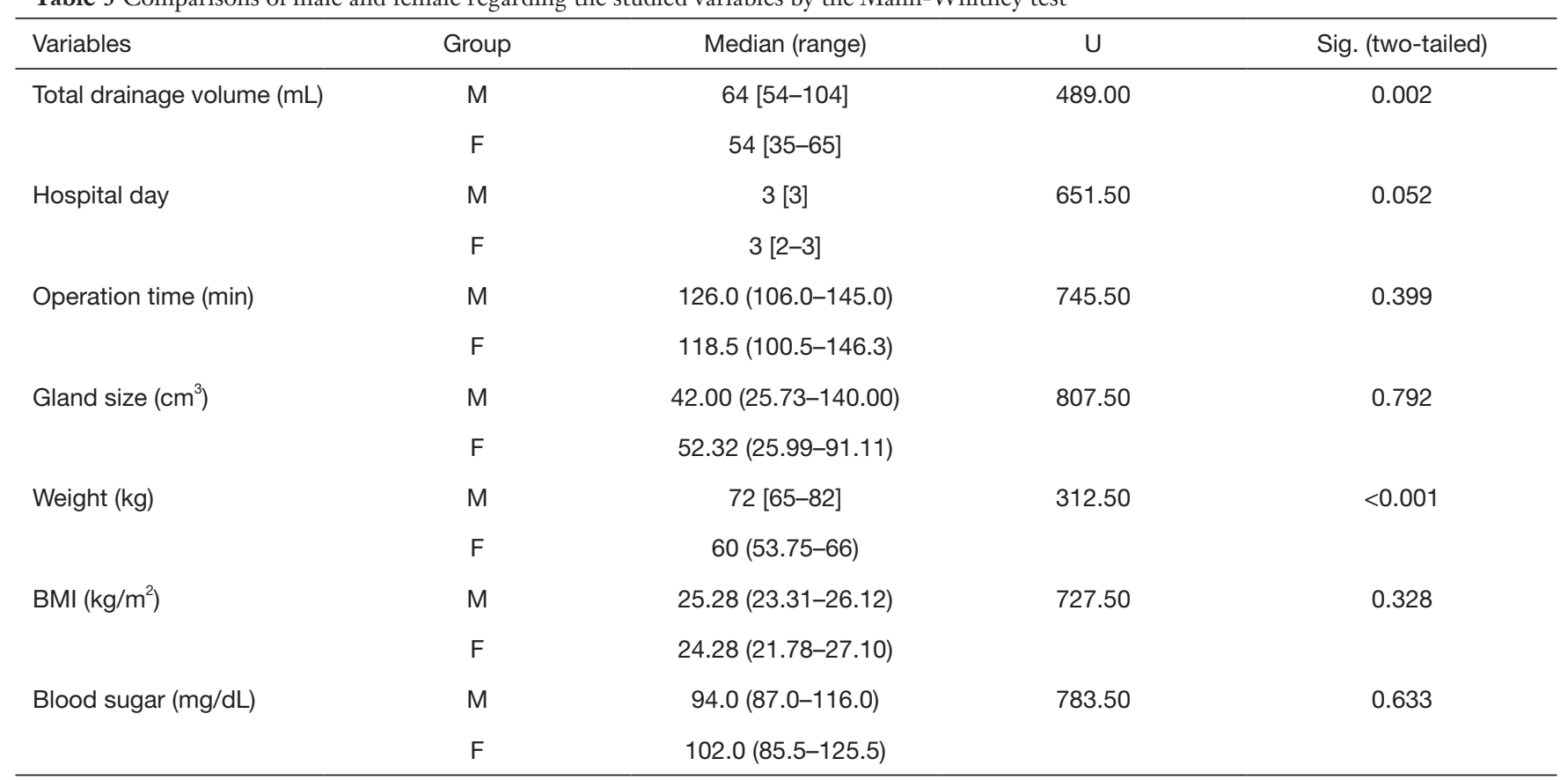

BMI, body mass index.

$(\beta=0.173 ; 95 \% \mathrm{CI}, 0.087-0.260 ; \mathrm{P}<0.001)$, and larger thyroid gland size ( $\beta=0.069 ; 95 \% \mathrm{CI}, 0.008-0.130 ; \mathrm{P}=0.027$ ) turned out to be independent risk factors for the total drainage volume.

\section{Discussion}

As improvement of surgical technique, applying of topical hemostatic agents, and introduce of novel energy device such as LigaSure or Harmonic Scalpel, studies have revealed that routine drainage is unnecessary after thyroid surgeries (4). Indeed, previous studies have shown that the use of drains lengthened the hospitalization and suggested that drains should only be used in the presence of extensive dead space (5). It has been reported that there is no significant difference in the incidence of postoperative hematoma or seroma in patients for whom postoperative drains were or were not placed $(6,7)$. In our practice, we used cold instruments rather than surgical energy devices during the operation and inserted drains on all of the patients in the study. Therefore, we took the opportunity to investigate which factors might have influenced the drainage output.

The time of the day that the surgery ends has a significant effect on the day-1 drainage volume. Hence, considering the variable completion time of the surgeries, we substituted the total post-operative drainage volume with the day-1 drainage volume. The total post-operative drainage volume was regarded as the time the drainage tube was inserted at the time of surgery until the time it was removed. Since the drains were removed when there was minimal output, the uncalculated volume of drainage fluid was insignificant. The median total drainage volume was $56 \mathrm{~mL}$ (Table 2). If suction drain was not used, waiting for the fluid to be absorbed by itself might cause some discomfort to the patient.

Table 6 shows a reduction in gland size when moving from Bethesda group I to Bethesda group VI (8). This could be explained by the fact that the higher risk of malignancy to group VI forced the patients to receive the operation even when the lesion was still small; on the contrary, patients with group I fine needle aspiration data might choose to avoid surgery until the lesion is big enough to cause symptoms or cosmetic concern.

Multivariate analysis showed that men had a higher drainage volume than women; this is consistent with the findings of Burkey et al. (9), Promberger et al. (10), and Calò et al. (11). Although the reasons for this difference remain unknown, it may be that the male muscles are stronger and their contractions, at awakening, provoke 
Table 6 Comparisons of FNAC groups regarding the studied variables by the Kruskal-Wallis test

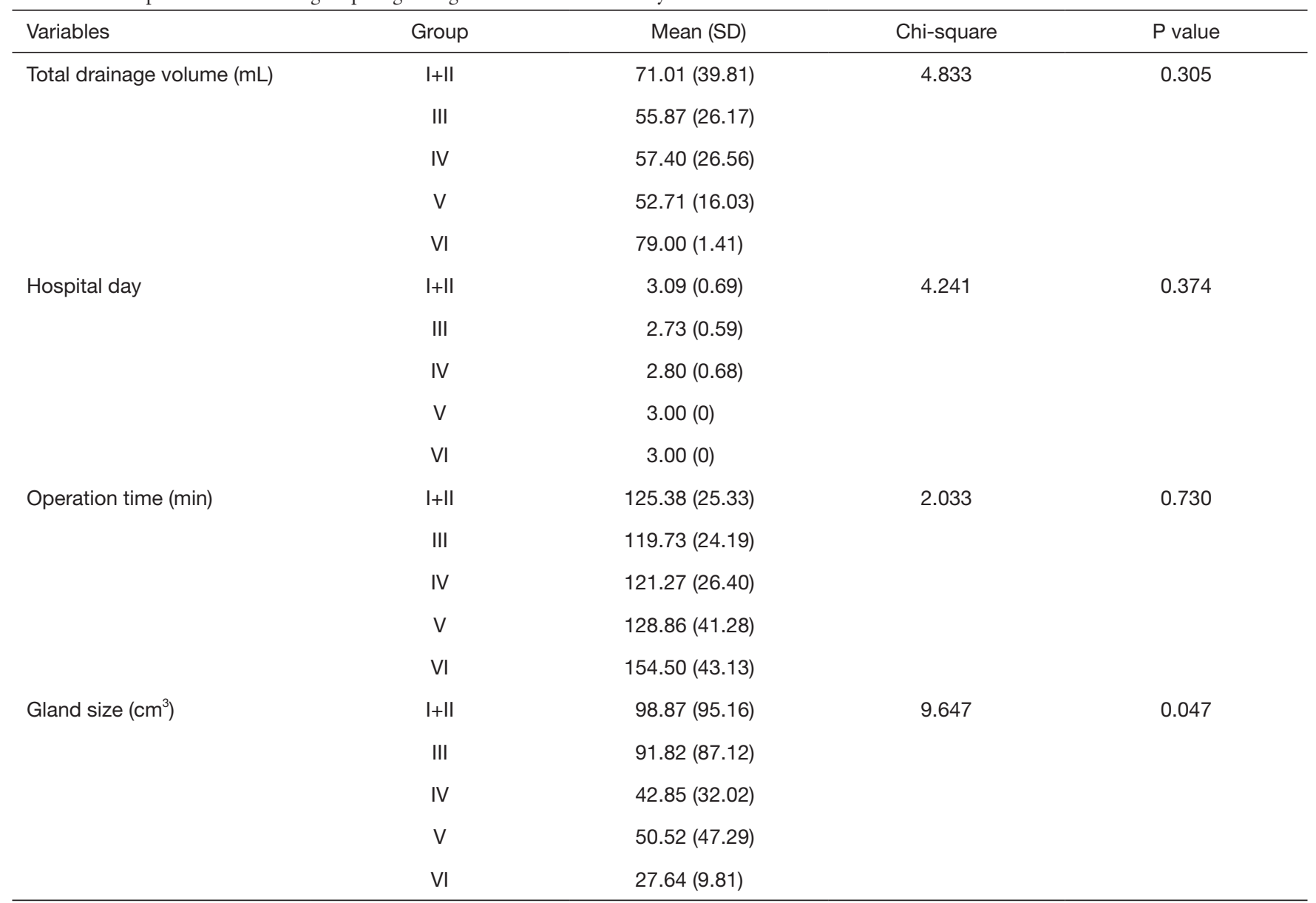

$\mathrm{df}=4$. FNAC, fine-needle aspiration cytology.

Table 7 Chi-square test for the association between FNAC groups and malignancy

\begin{tabular}{lccr}
\hline FNAC group & Benign & Malignant & Total \\
\hline I+II & $29(90.6)$ & $3(9.4)$ & $32(45.1)$ \\
III & $12(80.0)$ & $3(20.0)$ & $15(21.1)$ \\
IV & $12(80.0)$ & $3(20.0)$ & $15(21.1)$ \\
V & $3(42.9)$ & $4(57.1)$ & $7(9.9)$ \\
VI & $0(0.0)$ & $2(100.0)$ & $2(2.8)$ \\
Total & $56(78.9)$ & $15(21.1)$ & $71(100.0)$ \\
\hline
\end{tabular}

$\chi^{2}=15.591 ; \mathrm{df}=4 ; \mathrm{P}=0.004$. FNAC, fine-needle aspiration cytology.

the slipping of ligatures or reopening of previously ligated vessels causing hematomas (1). Blood sugar levels were also one of the factors affecting thyroid drainage, and hemorheological parameters (hematocrit, plasma proteins, erythrocyte aggregation, and erythrocyte deformability) in high blood sugar levels are often disturbed (12). Perioperative hyperglycemia was associated with adverse outcomes in general surgery patient; patients with hyperglycemia had a significantly increased risk of infection, reoperative interventions, and death (13). Moreover, our 
Table 8 Univariable and multivariable analysis of factors influencing total drainage volume

\begin{tabular}{|c|c|c|c|c|c|c|}
\hline \multirow{2}{*}{ Variable } & \multicolumn{3}{|c|}{ Univariable } & \multicolumn{3}{|c|}{ Multivariable } \\
\hline & $\beta$ & $\mathrm{Cl}$ & $P$ value & $\beta$ & $\mathrm{Cl}$ & $P$ value \\
\hline Age (years) & 0.648 & $0.198-1.097$ & 0.005 & 0.314 & -0.120 to 0.740 & 0.152 \\
\hline Weight (kg) & 0.868 & $0.341-1.395$ & 0.001 & - & - & - \\
\hline BMI $\left(k g / m^{2}\right)$ & 2.108 & $0.242-3.975$ & 0.027 & 0.678 & -1.150 to 2.500 & 0.466 \\
\hline $\mathrm{Hb}(\mathrm{g} / \mathrm{dL})$ & 0.592 & -3.120 to 4.310 & 0.754 & - & - & - \\
\hline 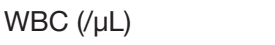 & 0.000 & -0.005 to 0.004 & 0.883 & - & - & - \\
\hline Free T4 (ng/dL) & 44.20 & $9.54-78.86$ & 0.012 & 24.50 & -4.17 to 53.18 & 0.094 \\
\hline Blood sugar (mg/dL) & 0.217 & $0.129-0.306$ & $<0.001$ & 0.173 & $0.087-0.260$ & $<0.001$ \\
\hline Malignant & -7.834 & -23.550 to 7.880 & 0.328 & - & - & - \\
\hline Gland size $\left(\mathrm{cm}^{3}\right)$ & 0.102 & $0.030-0.174$ & 0.005 & 0.069 & $0.008-0.130$ & 0.027 \\
\hline
\end{tabular}

$\beta$, regression coefficient; $\mathrm{Cl}$, confidence interval; $\mathrm{BMI}$, body mass index; WBC, white blood cell; TSH, thyroid stimulating hormone.

study showed that high blood sugar levels increased the total drainage volume. The third factor affecting the postsurgery drainage volume was the size of the resected thyroid lobe; the size of the thyroid nodule or goiter is often used as an indication to insert drains (14). A study by Dunlap et al. (15). demonstrated that some lobectomy procedures with a very dry surgical dissection have still developed significant postoperative drainage. Surgeons traditionally leave a drain following thyroid surgery with the hope that this will obliterate the dead space and evacuate any collected blood and serum (16). We believe that a thyroid lobectomy of a larger size will leave a larger dead space for accumulating more blood.

In the current study, the operations were performed by the same surgeon, with the same technique and procedures. Therefore, any bias caused by operator's habits was minimized. The results (Table 4) showed the right-sided thyroid lobectomies took more time than left-sided; one possible explanation is that our surgeon is right-handed, and this may have made some of the steps during the operation easier in left-sided thyroid lobectomies.

There are several limitations to our study. First, the drainage volume was documented once daily; hence, we were unable to determine the change in drainage output within a day. Second, most hematomas are clinically apparent 2-4 hours after surgery, $75 \%$ of life-threatening hematomas develop within the first 6 hours of thyroid surgery, and the remainder mainly occur in the following 6-24 hours (17). If we could collect data every hour, then the drain could have been removed earlier; thus, drain complications could be minimized. Finally, the study did not include a control group without a drain; drains do not necessarily prevent hematoma as they get clogged with blood clots (18). Thus, there have been several discussions regarding whether the use of drains has been vital in avoiding this complication. However, there are studies that appear to suggest no benefit of drainage insertion after uncomplicated thyroidectomy (19).

\section{Conclusions}

The trend of performing thyroid surgery without the use of a drain has increased in recent years. Placing a drain should never be considered as a suitable substitute for meticulous surgical technique with careful hemostasis. According to our study, male sex, larger thyroid gland, and higher 
blood sugar level are independent risk factors for increased drainage volume. Patients with these factors should undergo thorough hemostasis, and bleeding should be intensively monitored during the perioperative period.

\section{Acknowledgments}

Funding: This work was supported by grants from the Research Found of Tri-Service General Hospital (TSGH-C107-023, TSGH-C108-041), Taipei.

\section{Footnote}

Conflicts of Interest: The authors have no conflicts of interest to declare.

Ethical Statement: The authors are accountable for all aspects of the work in ensuring that questions related to the accuracy or integrity of any part of the work are appropriately investigated and resolved. The study protocol was reviewed and approved by the institutional review board of the Tri-Service General Hospital, National Defense Medical Center, Taipei (approval number: 1-107-05-166).

\section{References}

1. Chen E, Cai Y, Li Q, et al. Risk factors target in patients with post-thyroidectomy bleeding. Int J Clin Exp Med 2014;7:1837-44.

2. Woo SH, Kim JP, Park JJ, et al. Comparison of natural drainage group and negative drainage groups after total thyroidectomy: prospective randomized controlled study. Yonsei Med J 2013;54:204-8.

3. Campbell MJ, McCoy KL, Shen WT, et al. A multiinstitutional international study of risk factors for hematoma after thyroidectomy. Surgery 2013;154:1283-9; discussion 1289-91.

4. Docimo G, Tolone S, Conzo G, et al. A GelatinThrombin Matrix Topical Hemostatic Agent (Floseal) in Combination With Harmonic Scalpel Is Effective in Patients Undergoing Total Thyroidectomy: A Prospective, Multicenter, Single-Blind, Randomized Controlled Trial. Surg Innov 2016;23:23-9.

5. Deveci U, Altintoprak F, Sertan Kapakli M, et al. Is the Use of a Drain for Thyroid Surgery Realistic? A Prospective Randomized Interventional Study. J Thyroid Res 2013;2013:285768.

6. Sanabria A, Carvalho AL, Silver CE, et al. Routine drainage after thyroid surgery--a meta-analysis. J Surg Oncol 2007;96:273-80.

7. Harding J, Sebag F, Sierra M, et al. Thyroid surgery: postoperative hematoma--prevention and treatment. Langenbecks Arch Surg 2006;391:169-73.

8. Cibas ES, Ali SZ. The 2017 Bethesda system for reporting thyroid cytopathology. Thyroid 2017;27:1341-6.

9. Burkey SH, van Heerden JA, Thompson GB, et al. Reexploration for symptomatic hematomas after cervical exploration. Surgery 2001;130:914-20.

10. Promberger R, Ott J, Kober F, et al. Risk factors for postoperative bleeding after thyroid surgery. Br J Surg 2012;99:373-9.

11. Calò PG, Pisano G, Piga G, et al. Postoperative hematomas after thyroid surgery. Incidence and risk factors in our experience. Ann Ital Chir 2010;81:343-7.

12. Cho YI, Mooney MP, Cho DJ. Hemorheological Disorders in Diabetes Mellitus. J Diabetes Sci Technol 2008;2:1130-8.

13. Kwon S, Thompson R, Dellinger P, et al. Importance of perioperative glycemic control in general surgery: a report from the Surgical Care and Outcomes Assessment Program. Ann Surg 2013;257:8-14.

14. Schietroma M, Pessia B, Bianchi Z, et al. Thyroid Surgery: To Drain or Not to Drain, That Is the Problem - A Randomized Clinical Trial. ORL J Otorhinolaryngol Relat Spec 2017;79:202-11.

15. Dunlap WW, Berg RL, Urquhart AC. Thyroid drains and postoperative drainage. Otolaryngol Head Neck Surg 2010;143:235-8.

16. Khanna J, Mohil RS, Chintamani, et al. Is the routine drainage after surgery for thyroid necessary? A prospective randomized clinical study. BMC Surg 2005;5:11.

17. Woods RS, Woods JF, Duignan ES, et al. Systematic review and meta-analysis of wound drains after thyroid surgery. Br J Surg 2014;101:446-56.

18. Ernst R, Wiemer C, Rembs E, et al. Local effects and changes in wound drainage in the free peritoneal cavity. Langenbecks Arch Chir 1997;382:380-92.

19. Kalemera Ssenyondo E, Fualal J, Jombwe J, et al. To drain or not to drain after thyroid surgery: a randomized controlled trial at a tertiary Hospital in East Africa. Afr Health Sci 2013;13:748-55.

Cite this article as: Chen CY, Chiu YL, Rajbhandari S, Cheng SY, Lin HC, Chu YH, Lee JC. Predictive factors of increased surgical drain output after thyroid lobectomy: a retrospective study. Gland Surg 2019;8(5):542-549. doi: 10.21037/gs.2019.10.05 